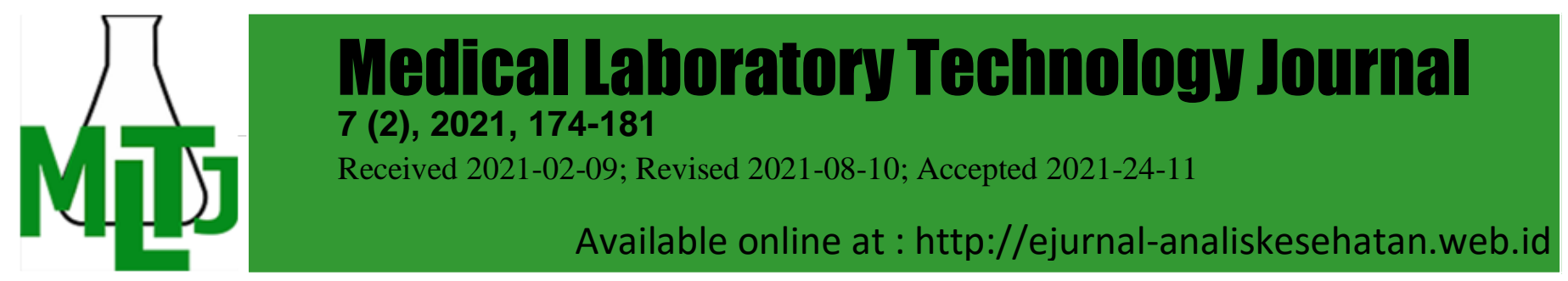

\title{
Evaluation of Vitamin D-levels and Bone Mineral Density in Lymphoma and Solid Tumors of Childhood after Treatment
}

\author{
*Özge Tanıdır Artan¹, Suna Emir² \\ ${ }^{1}$ Department of Pediatrics, Health Science University, Ankara City Hospital, Ankara, \\ Turkey. ${ }^{2}$ Department of Pediatric Hematology Oncology, Atılım University, Ankara, \\ Turkey. *E-mail: ozgetanidir@hotmail.com \\ DOI: $10.31964 / \mathrm{mltj} . v 7 \mathrm{i} 2.403$
}

\begin{abstract}
As the survival rate of childhood cancers increases, late effects of the treatment are becoming significantly more critical. This study evaluates serum 25 Hydroxy Vitamin D levels and bone mineral density (BMD) of patients with lymphoma and solid tumors. This study included patients diagnosed with cancer in Children's Hematology-Oncology Hospital, Ankara, Turkey, between 2004 and 2013. These patients were all in remission and completed their treatment. Patient data were collected from corresponding medical files. Vitamin D levels, BMD measurements, and other laboratory tests were performed prospectively after chemotherapy. The study group consisted of 105 patients who completed treatment at least one year ago. Overall, $59.6 \%$ of the subjects were found to have vitamin D levels less than $20 \mathrm{ng} / \mathrm{mL}$. When the factors affecting vitamin $D$ deficiency were evaluated, there were not any factors related to vitamin $\mathrm{D}$ deficiency. However, a positive correlation was observed in the blood sampling time. Namely, test results are taken in the summer months (AprilSeptember) were higher. In our study, bone mineralization disorder (low BMD) was found in $44.4 \%$ of the patients. Bone health was significantly affected in children who recovered from cancer. Physicians who assess these children who recovered from cancer must pay necessary attention to these patients' nutrition, vitamin supplementations, and physical activities from the start of diagnosis and continued follow-up in terms of possible complications.
\end{abstract}

Keywords: 25-hydroxy vitamin D; bone mineral density; lymphoma; solid tumor.

\section{INTRODUCTION}

The survival rate in childhood cancers has significantly increased with chemotherapy $(\mathrm{CT})$, radiotherapy $(\mathrm{RT})$, and intensive care. As the survival rate increases, the late effects of treatment are becoming more critical. They may occur months or years after the treatment. As children's growth and development process continue, they become more susceptible to these late effects. These effects may vary depending on the tumor itself, the treatment regimen (surgery, CT, and RT), the age at diagnosis and treatment, and the time elapsed in remission. Several earlier studies have noted that survivors of pediatric cancers have a higher risk of vitamin $D$ insufficiency or deficiency. This risk depends on the tumor itself, treatment regimens, poor nutrition. (Andıran et al., 2012; Choudhary et al., 2013; Sinha et al., 2011; Simmons et al., 2011; Rossen et al., 2013). However, these studies targeted patients that recovered from leukemia, not solid tumors and lymphoma.

Earlier studies have noted that bone mineral density typically decreases in patients undergoing cancer treatment (Sala et al., 2007). Osteopenia may also occur during diagnosis due to increased metabolism, the release of tumor cytokines, and a change in bone mineralization density. During the treatment period, corticosteroids 
therapy, low levels of physical activity, and poor nutrition significantly increase osteoporosis and fracture risk in patients who are already osteopenic. (Sala et al., 2007). There have been studies of vitamin $D$ levels in patients recovering from leukemia, and there have been studies of BMD in children with lymphoma. However, to our knowledge, there have been no studies in children with lymphoma and solid tumor after completion of chemotherapy. Thus, our study aimed to evaluate the levels of 25-hydroxy Vitamin D (vitamin D) and bone mineral density (BMD) of children with lymphoma and solid tumors after completing chemotherapy.

\section{MATERIALS AND METHODS}

Patients diagnosed with lymphoma and solid tumor in Children's HematologyOncology Hospital, Ankara, Turkey, between 2004 and 2013 were included in the study. They were all in remission and completed the treatment at least one year ago. Patient data on age, gender, primary diagnosis, treatment details were collected from corresponding medical files. Vitamin D levels, BMD measurements, and other laboratory tests were performed prospectively after treatment. Before starting the study, approval was obtained from Ankara Childrens' Hematology and Oncology hospital ethics committee (Date: 06.06.2013, Decision No: 158). The subjects were included in the study after verbal consent was obtained from those who accepted to be included and from their families when they were invited to participate in the study.

The data collection process recorded sex, age, diagnosis, stage, diagnosis age, treatment, chemotherapy, and radiotherapy information of all patients included in the study. Chemotherapeutics and their total doses were calculated during the treatment period. Radiotherapy doses and regions were recorded in patients receiving radiotherapy. Bone mineral density (BMD) was measured from the lumbar region (L2L4) by Dual Energy X-Ray Absorptiometry (DEXA) using the Hologic QDR-4500A (S / N 45780) ( According to normal BMD values, deviations were expressed as Z-score calculated according to a healthy control group of the same age and sex in children. Bone mineral density Z-score lower than -2.5 standard deviation (SD) is considered osteoporosis, and Z-score was between -1-2.5 SD is considered osteopenia.

The venous blood sample taken in the routine follow-up examinations was used in laboratory investigations; Serum Ca, P, ALP, PTH-intact tests were studied in the central laboratory to evaluate the metabolism of vitamin D. Ca, P, ALP were studied by colorimetric method (Beckman Coulter) ${ }^{\circledR}$ AU-680 autoanalysers. Serum PTH chemiluminescence was measured using immunometric method (Beckman Coulter) ® UniCel Dxl 800 with autoanalysers. Plasma Vitamin D levels were studied using MS / MS (Agilent Technologies) ® methods. The effects of all these data on vitamin $\mathrm{D}$ and bone mineralization levels were investigated.

SPSS did a statistical analysis of the data for Windows (version 11.5). In the two-category comparisons, the Student t-test was used for the variables with normal distribution. For the categorical data, the Chi-Square test was applied in the relations. In addition, Pearson and Spearman Rank correlation analyses were used to evaluate the relationships between the variables. The statistical significance limit of the study was accepted as 0.05 .

There were 105 patients with lymphoma and solid tumors in this study who were in remission after cancer treatment. The mean age of the patients at the time of diagnosis was $6.77 \pm 4.51$ years ( 6 months-19 years). The mean follow-up period was $4.76 \pm 3.00$ years (1.5-13 years). The follow-up period after treatment was $3.56 \pm 2.76$ years (1-12.5 years). The distribution of patients in terms of diagnosis is as follows; 45 
patients were diagnosed with lymphoma, and 60 patients were diagnosed with solid tumor. There was Hodgkin lymphoma in 28 patients, Non-Hodgkin Lymphoma in 19 patients, Wilms tumor in 19 patients, central nervous system tumors in 12 patients, rhabdomyosarcoma in 8 patients, neuroblastoma in 6 patients, and 13 patients with other tumor types. There were 67 female and 38 male patients. At the time of diagnosis, the patients were divided into two groups. Patients with stage 1,2 , and nonmetastatic stages are considered in the early stage; stages 3,4 , and metastatic patients were evaluated as the advanced stage. $47.6 \%(n=39)$ of the patients were in the early stage group and $52.4 \%(n=43)$ were in the advanced stage group. When the time of blood sampling was evaluated, it was observed that in $53.8 \%$ of the patients $(n=56)$, the blood sample was taken in winter months (October-March), and in $46.2 \%$ of the patients $(n=49)$, it was taken in summer months (April-September). Demographic data of patients are summarized in Table 1.

Table 1. General Features of the Study Population $(n=105)$.

\begin{tabular}{l|c}
\hline Male & 67 \\
Female & 38 \\
Age [year, mean \pm SD, (range)] & \\
At the time of diagnosis & $6.77 \pm 4.51$ (6 months-19 years) \\
At the time of study & $11.82 \pm 5.10$ (3-28 years) \\
Follow up period after treatment & $4.76 \pm 3.00$ (1.5-13 years) \\
[years, mean \pm SD, (range)] & \\
Stage & 39 \\
1 and 2 (early stages) & 43 \\
3 and 4 (advanced stages) & 23 \\
Stage Not specified & \\
Tumor types & 28 \\
Hodgkin Lymphoma & 19 \\
Non-Hodgkin Lymphoma & 19 \\
Wilms Tumor & 12 \\
CNS Tumors & 8 \\
Rhabdomyosarcoma & 6 \\
Neuroblastoma & 13 \\
Others &
\end{tabular}

Vitamin D Results: The mean of vitamin D results was $18.40 \pm 38.99 \mathrm{ng} / \mathrm{ml}(4-56$ $\mathrm{ng} / \mathrm{ml})$. Vitamin $D$ values were found to be low $(<15 \mathrm{ng} / \mathrm{ml})$ in $31(28.4 \%)$ patients. Vitamin D values were found to be insufficient $(15-20 \mathrm{ng} / \mathrm{ml})$ in $34(31.2 \%)$ patients. Vitamin D values were normal $(>20 \mathrm{ng} / \mathrm{ml})$ in $40(36.7 \%)$ patients as shown in Table 2. The mean Ca levels of all patients were $9.88 \pm 0.47 \mathrm{mg} / \mathrm{dl}(8.70-10.80 \mathrm{mg} / \mathrm{dl})$, the mean of $P$ values were $4.52 \pm 0.81 \mathrm{mg} / \mathrm{dl}(2.20-6.60 \mathrm{mg} / \mathrm{dl})$, the mean ALP values were $229.07 \pm 99.26 \mathrm{U} / \mathrm{L}(90-528 \mathrm{U} / \mathrm{L})$.

PTH values were $45.85 \pm 20.84 \mathrm{pg} / \mathrm{ml}(13.20-133 \mathrm{pg} / \mathrm{ml})$. PTH elevation was not observed in patients whose Vitamin $D$ levels were lower than 20 . When the factors affecting vitamin $\mathrm{D}$ deficiency were evaluated; age, gender, use of radiotherapy and chemotherapy, tumor type were not correlated with the level of vitamin D. While vitamin $D$ measurements were low in winter months (October-March), it was observed that tests in summer were higher $(p<0.05)$ than any other season. A detailed presentation of vitamin D status for 105 patients is summarized in Table 2. 
Table 2. Detailed Analysis of Vitamin D Status for 105 Patients.

\begin{tabular}{|c|c|c|c|}
\hline & $\begin{array}{l}\text { Deficiency } \\
\text { (Vit. D }<15 \mathrm{ng} / \mathrm{ml} \text { ) } \\
\text { No. of pts (\%) }\end{array}$ & $\begin{array}{l}\text { Insufficiency } \\
\text { (Vit. D :15-20 ng/ml) } \\
\text { No. of pts (\%) }\end{array}$ & $\begin{array}{l}\text { Sufficiency } \\
\text { (Vit. D > } 20 \mathrm{ng} / \mathrm{ml} \text { ) } \\
\text { No. of pts (\%) }\end{array}$ \\
\hline \multicolumn{4}{|l|}{ Age } \\
\hline$<5$ years & $2(40)$ & $0(0)$ & $3(60)$ \\
\hline $5-10$ years & $12(28.6)$ & $16(38.1)$ & 14 (33.3) \\
\hline$>10$ years & 17 (29.3) & $18(31.0)$ & $23(39.7)$ \\
\hline \multicolumn{4}{|l|}{ Gender } \\
\hline male & $16(24.2)$ & $24(36.4)$ & $26(39.4)$ \\
\hline female & $15(35.9)$ & $10(25.6)$ & $14(35.9)$ \\
\hline \multicolumn{4}{|l|}{ Radiotherapy } \\
\hline $\begin{array}{l}\text { Patients treated } \\
\text { with RT }\end{array}$ & $18(36.0)$ & $14(28.0)$ & $18(36.0)$ \\
\hline $\begin{array}{l}\text { Patients not } \\
\text { treated with RT }\end{array}$ & $13(23.6)$ & $20(36.4)$ & $22(40.8)$ \\
\hline \multicolumn{4}{|l|}{ CT regimen } \\
\hline Steroid & $8(30.8)$ & $11(42.3)$ & $7(26.9)$ \\
\hline Cisplatin & $10(29.6)$ & $12(34.3)$ & $15(37.1)$ \\
\hline Other & $13(30.2)$ & $11(25.6)$ & 19 (44.2) \\
\hline \multicolumn{4}{|l|}{ Season } \\
\hline Winter & $21(37.5)$ & $18(32.1)$ & $17(30.4)$ \\
\hline Summer & $10(22.2)$ & $13(28.9)$ & $22(48.9)$ \\
\hline \multicolumn{4}{|l|}{ Diagnosis } \\
\hline Lymphoma & $15(32.6)$ & $16(34.8)$ & $15(32.6)$ \\
\hline Solid Tumors & $16(27.1)$ & $18(30.5)$ & $25(42.4)$ \\
\hline \multicolumn{4}{|l|}{ Stage } \\
\hline Early & $9(23.7)$ & $13(34.2)$ & $16(42.1)$ \\
\hline Advanced & $15(36.6)$ & $13(31.7)$ & $13(31.7)$ \\
\hline
\end{tabular}

Bone Mineral Density Results: The bone mineral density of the patients was evaluated with Dexa in 99 children. Z-scores of the patients according to age was corrected using the oxology 2014 package program. The mean of the DEXA Z-score was $(-0.59) \pm 1.25[(-3.80)-3.08]$, and the mean BMD $(\mathrm{g} / \mathrm{cm} 2)$ was $0.641 \pm 0.168$ $(0.399-1.053)$. Out of 99 patients, 55 patients $(55.6 \%)$ are diagnosed with a normal BMD z-score, 41 (41.4\%) patients had a low BMD z-score [(-1.00) - (- 2.5)] (osteopenia), and 3 patients (3.0\%) were found to be severe [-2.5 and under] (osteoporosis). The results are summarized in Table 3.

Table 3. BMD Z-score Analysis on Our Patient Set.

\begin{tabular}{lccc}
\hline & Normal $(>-1)$ & Osteopenia $(-1,-2.5)$ & Osteoporosis $(<-2.5)$ \\
\hline $\begin{array}{l}\text { No of Patients / } \\
\text { Percentage }\end{array}$ & $55 / 55.6$ & $41 / 41.4$ & $3 / 3$ \\
$\begin{array}{l}\text { Mean BMD }(\mathrm{g} / \\
\left.\mathrm{cm}^{2}\right) \text { level }\end{array}$ & $0.641 \pm 0.168(0.399-1.053)$ \\
$\begin{array}{l}\text { Mean DEXA z- } \\
\text { score level }\end{array}$ & $(-0.59) \pm 1.25[(-3.80)-3.08]$ \\
\hline
\end{tabular}


Children are more sensitive to the late effects of cancer treatment as they are in growth and development. These effects include endocrine system problems, metabolic problems, pulmonary and cardiovascular problems, learning difficulties, psychological problems, and secondary cancer development.

Late side effects of the endocrine system are more common, as noted in many earlier studies (Bhatia et al., 2006; Cohen, 2003; Bircan, 2003; Nandagopal et al., 2008). Changes in bone mineral density, growth retardation, malnutrition, and obesity are common problems in cancer treatment children. $25-\mathrm{OH}$-vitamin $\mathrm{D}$ is the major circulating form of vitamin $\mathrm{D}$, and its analysis is recommended to show vitamin D status. In this study, we evaluated bone mineral density levels and $25 \mathrm{OH}$-vitamin D status in children with lymphoma and solid tumors after completion of therapy.

In our study, vitamin D deficiency and deficiency rate was found to be higher when compared with the average population in Turkey (Bircan et al. 2003, Andıran et al., 2012). The prevalence of vitamin $D$ deficiencies in the average population is 14$49 \%$ in Turkey. In a recent study by Andıran N. et al., 440 children were evaluated in Ankara between the ages of $0-16$, and $40 \%$ of the cases were observed to have vitamin D levels below $20 \mathrm{ng} / \mathrm{ml}$ (5). Compared with healthy children, the rate of low vitamin $\mathrm{D}$ levels was significantly higher in our study group with pediatric cancer. $59.6 \%$ of the subjects were found to have vitamin D levels less than $20 \mathrm{ng} / \mathrm{mL}$.

In a recent study by Choudhary et al., 484 patients were evaluated after cancer treatment, and a vitamin D deficiency rate was determined in $29 \%$ of the patients. In this study, vitamin D deficiency was associated with puberty (Tanner phase 3-5) and race (Non-Hispanic African origin, Asian origin, Hispanic origin). BMl, gender, diagnosis, RT, and steroid use were not associated with vitamin D levels (6).

In another study, Sinha et al. reported that vitamin D deficiency was significantly higher in the patient group $(21.3 \%)$ of those who received cancer treatment than in the control group (3.3\%). Age, black ethnic origin, winter season, and cancer disease were reported as risk factors in the study (Sinha et al., 2011). In another study by Simmons $\mathrm{JH}$ et al., 78 patients were evaluated after the treatment of acute lymphoblastic leukemia (ALL), and $12 \%$ of them were found to be vitamin D deficient $(<15 \mathrm{ng} / \mathrm{ml})$. In contrast, 53 of them were found to be vitamin $D$ insufficient $(15-30 \mathrm{ng} / \mathrm{ml})$. Increasing vitamin $D$ levels at a young age, increased dietary vitamin D intake increased vitamin D support. Increased exposure to sunlight was observed to have a positive effect, while treatment type, race, sex, diagnosis, time after diagnosis, and BMI were found not to affect the outcome (Simmons JH et al., 2011).

Rossen et al. reported that the mean vitamin D value was $29.8 \mathrm{ng} / \mathrm{ml}$; it was observed that vitamin D deficiency was $14.4 \%$, and failure was $39.3 \%$ during the postremission study. The decrease in time was found to be $11.4 \%$, and this figure was found to be statistically significant $(p<0.0001)$. The results of earlier vitamin $D$ deficiency studies are summarized in Table 4. To our knowledge, in our study, the lowest vitamin $\mathrm{D}$ levels were determined in children with cancer compared to other previously published studies from different countries. Another interesting finding in our study is that vitamin D deficiency was unrelated to the treatment content, steroid usage, cumulative chemotherapy dosage, and radiotherapy use.

In our study, the rate of osteopenia was $41.4 \%$, and the osteoporosis rate was $3.0 \%$, as illustrated in Table- 3 . The low bone mineral density ratio was approximately $45 \%$ in total. In studies, this rate varies concerning diagnosis, treatment, and time after treatment. Kaste et al. reported a low bone mineral density rate of $26 \%$ with quantitative computed tomography in 99 patients with a mean duration of 7.2 years. Othman et al. reported that the rate of osteopenia was $26 \%$, and the 
osteoporosis rate was 16\% in 31 patients with Wilms tumor (Othman et al., 2002). Sala et al. reported that the rate of osteopenia is $45 \%$ in patients with lymphoma whose treatment was terminated at least one year ago (Sala et al., 2007). Odame et al. reported the rate of osteopenia as $44 \%$ in 25 patients with brain tumors with a mean follow-up of 7.4 years (Odame et al., 2006).

Maniadaki et al. reported, 17 (group 1) at the beginning of the treatment, 16 (group 2) at the initiation of KT, and ten patients with ALL (10 patients) who had been treated at the end of the study, the BMD $z$ score was $-0.74 \pm 0.32,-1.59 \pm 0.24,-2.03 \pm$ 0.27 respectively (Maniadaki et al., 2006). They found a statistically significant difference between groups 1 and 3 . The ratio of patients with BMD <- two was reported to be $17 \%$ in group $1,25 \%$ in group 2 , and $50 \%$ in group 3 . Kaste et al. reported that the rate of osteoporosis was $44.3 \%$, and the rate of osteopenia was $41.4 \%$ in $70 \mathrm{ALL}$ patients with a mean follow-up of $4.9 \pm 2.5$ years (Kaste et al., 2001). In the analysis of risk factors on BMD, daily calcium intake yielded significant results. The duration of treatment, cranial radiotherapy, and cumulative steroid dose did not significantly affect BMD levels. These studies show that the rate of decrease in BMD levels increases as the duration of treatment increases and it reaches the highest rate at the end of treatment. In our study, DEXA evaluation of patients was performed after the completion of treatment. The DEXA measurements of the patients were not taken before the treatment. Thus, it was not possible to compare the changes at the end of the diagnosis and treatment. However, literature in children and adults shows that oncologic treatment increases BMD. Furthermore, most of these studies describe the low rates of BMD in different stages of treatment protocols (Odame et al., 2006; Maniadaki et al., 2006).

When the literature is reviewed, it is seen that a low BMD ratio has been reported in a wide range from $25 \%$ to $85 \%$ (Kaste et al., 2001; Bechard et al., 2015). In the literature, the rate of BMD in children with cancer was mainly investigated in patients with leukemia. The rate of BMD in these patients varies between $21-85 \%$ (Kaste et al., 2001; Bechard et al., 2015). The rates in patients with lymphoma and solid tumors are between 26-65\% (Bechard et al., 2015). In our study, similarly, the low BMD rate was found to be $44.4 \%$. Therefore, the results should be evaluated carefully. Because it is one of the influential factors in the studies, the methods, diagnostic groups, applied treatments, and follow-up periods of BMD vary. In addition, vital differences such as nutrition and activity and hereditary factors, which affect BMD, have not been addressed in most of these studies.

Table 4. A Comparison of Vitamin D Deficiency in Studies.

\begin{tabular}{lccc}
\hline Study & No of subjects & Age & Vitamin D Deficiency \\
\hline Andıran et al., 2012 & 440 & $0-16$ & $40 \%$ \\
Chaudry et al., 2013 & 484 & $0-18$ & $29 \%$ \\
Sinha et al., 2011 & 61 & $1.5-24$ & $21.3 \%$ \\
Simmons et al., 2011 & 78 & $8-21$ & $53 \%$ \\
Rossen et al., 2013 & 201 & - & $53.7 \%$ \\
Artan et al., 2021 & 105 & $0-18$ & $59.6 \%$ \\
\hline
\end{tabular}

There were some limitations associated with our study. Since we used retrospective data on patients' data retrospectively obtained from hospital records of our study group, there is a lack of data regarding BMI, social status, time spent under daylight, dressing habits, and daily vitamin $D$ intake of children. Vitamin D levels, BMD measurements, and other laboratory tests are performed prospectively. The methods, 
diagnostic groups, applied treatments, and follow-up periods of BMD vary. In addition, vital differences such as nutrition and activity and hereditary factors, which affect BMD, have not been addressed in most of these studies. Additionally, this is a one-center study held in Ankara; thus, it does not reflect the status of all Turkish children.

\section{CONCLUSION}

In conclusion, vitamin D levels in children with lymphoma and solid tumors are markedly lower than healthy children in our country, Turkey. Our study is important in terms of reflecting vitamin D status in children with cancer in Turkey. Comparing studies investigating vitamin $D$ status in children with cancer, the lowest vitamin D rate was found in our study population. It was also noticed that bone strength was significantly affected by the children who recovered from cancer. Physicians who assess these children who recovered from cancer must pay necessary attention to these patients' nutrition, vitamin supplementations, and physical activities from the start of diagnosis and continued follow-up in terms of possible complications.

\section{ACKNOWLEDGEMENT}

Thanks to all contributors for this research to be done.

\section{CONFLICT OF INTEREST}

The authors have no potential conflicts of interest regarding this study.

\section{REFERENCES}

Andıran, N., Celik, N., Akca, H., \& Doğan, G. (2012). Vitamin D deficiency in children and adolescents. Journal of clinical research in pediatric endocrinology, 4(1), 25.

Bechard, L. J., Gordon, C., Feldman, H. A., Venick, R., Gura, K., Guinan, E. C., \& Duggan, C. (2015). Bone loss and vitamin D deficiency in children undergoing hematopoietic cell transplantation. Pediatric blood \& cancer, 62(4), 687-692.

Bhatia, S., Blatt, J., \& Meadows, A. T. (2006). Late effects of childhood cancer and its treatment. In: Pizzo P.A., Poplack D.G. (eds). Principles and practice of pediatric oncology. 5th edition. Philadelphia: Lippincott Williams and Wilkins, 5, 14901514.

Bircan, İ. (2003). Malign hastalıkların endokrin etkileri. Günöz H, Öcal G, Yordam N, Kurtoğlu S (editörler). Pediatrik endokrinoloji. 1. edition. Ankara: Pediatrik Endokrinoloji ve Oksoloji Derneği Yayınları, 623-38.

Choudhary, A., Chou, J., Heller, G., \& Sklar, C. (2013). Prevalence of vitamin D insufficiency in survivors of childhood cancer. Pediatric blood \& cancer, 60(7), 1237-1239.

Cohen, L. E. (2005). Endocrine late effects of cancer treatment. Endocrinology and Metabolism Clinics, 34(3), 769-789.

Kaste, S. C., Jones-Wallace, D., Rose, S. R., Boyett, J. M., Lustig, R. H., Rivera, G. K., ... \& Hudson, M. M. (2001). Bone mineral decrements in survivors of childhood acute lymphoblastic leukemia: frequency of occurrence and risk factors for their development. Leukemia, 15(5), 728-734.

Kaste, S. C., Ahn, H., Liu, T., Liu, W., Krasin, M. J., Hudson, M. M., \& Spunt, S. L. (2008). Bone mineral density deficits in pediatric patients treated for sarcoma. Pediatric blood \& cancer, 50(5), 1032-1038.

Maniadaki, I., Stiakaki, E., Germanakis, I., \& Kalmanti, M. (2006). Evaluation of bone mineral density at different phases of therapy of childhood all. Pediatric hematology and oncology, 23(1), 11-18. 
Nandagopal, R., Laverdière, C., Mulrooney, D., Hudson, M. M., \& Meacham, L. (2008). Endocrine late effects of childhood cancer therapy: a report from the Children's Oncology Group. Hormone Research in Paediatrics, 69(2), 65-74.

Odame, I., Duckworth, J., Talsma, D., Beaumont, L., Furlong, W., Webber, C., \& Barr, R. (2006). Osteopenia, physical activity and health-related quality of life in survivors of brain tumors treated in childhood. Pediatric blood \& cancer, 46(3), 357-362.

Othman, F., Guo, C. Y., Webber, C., Atkinson, S. A., \& Barr, R. D. (2002). Osteopenia in survivors of Wilms tumor. International journal of oncology, 20(4), 827-833.

Rosen, G. P., Beebe, K. L., \& Shaibi, G. Q. (2013). Vitamin D levels differ by cancer diagnosis and decline over time in survivors of childhood cancer. Pediatric blood \& cancer, 60(6), 949-952.

Sala, A., Talsma, D., Webber, C., Posgate, S., Atkinson, S., \& Barr, R. (2007). Bone mineral status after treatment of malignant lymphoma in childhood and adolescence. European journal of cancer care, 16(4), 373-379.

Simmons, J. H., Chow, E. J., Koehler, E., Esbenshade, A., Smith, L. A., Sanders, J., \& Friedman, D. (2011). Significant 25-hydroxyvitamin D deficiency in child and adolescent survivors of acute lymphoblastic leukemia: Treatment with chemotherapy compared with allogeneic stem cell transplant. Pediatric blood \& cancer, 56(7), 1114-1119.

Sinha, A., Avery, P., Turner, S., Bailey, S., \& Cheetham, T. (2011). Vitamin D status in paediatric patients with cancer. Pediatric blood \& cancer, 57(4), 594-598. 